\title{
Analyzing suspension upright of a Formula Society of Automotive Engineers style vehicle
}

\author{
Greg Wheatley ${ }^{1}$, Darrin Gangemi ${ }^{1}$, Jarod Toogood $^{1}$, Rendage Sachini Sandeepa Chandrasiri ${ }^{2}$ \\ 1. College of Science and Engineering, James Cook University, Townsville, Australia \\ 2. Department of Chemistry, University of Colombo, Colombo 07, Sri Lanka \\ Corresponding author contact: greg.wheatleyejcu.edu.au
}

\begin{abstract}
This project was aimed at modeling the stress and deformation profile of a 6061-T6 aluminum suspension upright of a formula society of automotive engineer's style vehicle with a double wishbone suspension under the loading conditions of a $1.5 \mathrm{G}$ corner. With these results, it would need to be determined whether the design is fit for use. Using remote displacement boundary conditions for the upper and lower wishbone connections and the control arm connection with a remote force at the center of the wheel patch acting on the bearing surfaces the maximum stress, overall stress profile and maximum deformation of the upright was calculated. These results after, undertaking a verification and validation study, were a maximum equivalent von-Mises stress of 87.358MPa and a maximum bearing surface deflection of $0.21 \mathrm{~mm}$. The maximum von-Mises stress calculated was less than the fatigue limit of 90MPa signaling infinite life and also less than the yield stress of $240 \mathrm{MPa}$ signaling a safe design. Verification and validation techniques were used to ensure the final result was accurate and reflected the real - life system. Structural error was used to verify the results where it was found that maximum structural error in the upright was $0.052 \mathrm{~mJ}$ and at the location of maximum stress was between $0.0058-1.0782 \mathrm{e}-8 \mathrm{~mJ}$. Validation of the model was achieved by comparing the reaction forces calculated in ANSYS to theoretical values and was found that the magnitudes were within $2.5 \%$ of the theoretical values, thus the model was considered valid.
\end{abstract}

Keywords: Aluminum, Double wishbone, Stress, Structural error, Suspension

\section{$1 \quad$ Introduction}

Suspension uprights are a fundamental component of a vehicle suspension that provides a non-rotating bearing surface for the rotating wheel assembly relative to the chassis of the vehicle which uses a double wishbone suspension (Robert, 2010). This component typically has complex geometry due to suspension requirements, break caliper geometry and space limitations. A well-engineered upright is essential as it transmits tyre patch forces to the suspension and chassis as well as potentially being a contributor to the partially suspended mass (Sneh, 2014). The upright analyzed here is a rear upright. The suspensions geometries of front and rear wheels are different; such that the rear upright contains an upper aarm mount, lower a- arm mount and a control arm mount (Giovanni, 2015). Therefore, the aim of this project is to engineer a 6061-T6 aluminum upright for a formula society of automotive engineers (FSAE) style vehicle to withstand the forces present in a typical 1.5G corner using ANSYS Workbench.

ANSYS workbench is the software tool that will be used to simulate the behavior of the suspension upright under loading conditions of the $1.5 \mathrm{G}$ corner. It allows many simulation types but the one that will be used in this simulation is static structural. This is due to the nature of the loading in that it is a static load. Static structural analysis allows the geometry to be loaded into the workbench where appropriate meshing, boundary and loading conditions can be employed (Dhakar, 2016). ANSYS can also output information regarding stress, strain, deformation, fatigue life and safety factor. Meshing is an integral part of the analysis process as the mesh gives calculation points on the geometry. Therefore, finer the meshing the more accurate the results. However, with a finer meshing come higher calculation costs so a trade-off must be made (Agarwal, 2020). Due to the 3D nature of the load case and complexity of upright geometry, it will be analyzed using Finite Element Model (FEM) in ANSYS. 
Boundary conditions are another integral part of the analysis process. ANSYS offers a wide variety of boundary conditions that can simulate anything from a remote displacement to a bearing surface (Saurabh, 2016). It is imperative to have an understanding of how each boundary condition behaves so as to be able to simulate the model correctly. Loading conditions are next applied in order to simulate the forces acting on the model. ANSYS offers a variety of loading types however the one that is used in this simulation is the remote force which acts on the object from a remote location (Schommer, 2015). Furthermore, maximum deflection of the bearing surfaces as well as an overall stress profile of the upright geometry will be investigated. A verification and validation study will be undertaken with the results outlined in the report.

\section{Methodology}

The finite element analysis was done in a static structural analysis on ANSYS. It was then necessary to create the material 6061-T6 aluminum using the material properties outlined in Table 1 below,

Table 1. Properties of 6061-T6 Aluminum

\begin{tabular}{|c|c|}
\hline Property & Value \\
\hline Young's modulus & $69 \mathrm{GPa}$ \\
\hline Poisson's ratio & 0.33 \\
\hline Fatigue limit & $90 \mathrm{MPa}$ \\
\hline Yield stress & $240 \mathrm{MPa}$ \\
\hline Density & $2850 \mathrm{~kg} / \mathrm{m}^{3}$ \\
\hline
\end{tabular}

These properties as entered into ANSYS and the finite element analysis approach taken after this considered choosing the model and element type, the mesh density as well as approximating appropriate boundary conditions and external forces. The element type chosen was the triangular element as it best fit the model according to ANSYS.

To establish the mesh density by keeping low times for a course mesh sizing was used. After the simulation was done, the mesh was refined in areas of high stress and high error using a sphere of influence. According to Figure 1, sphere of influence A was used to refine the region of high stress. As this is an important result, high accuracy was necessary; firstly, the model was meshed with a medium sized mesh of $7 \mathrm{~mm}$. To evaluate the accuracy of this mesh, the structural error and generated stress profiles were analyzed. The purpose of this analysis was to identify regions where the mesh size could be refined. At areas of high stress and high error spheres of influence were added. This process was repeated until the maximum structural error was less than $0.1 \mathrm{~mJ}$. When the structural error was below this limit the result can be considered accurate. 


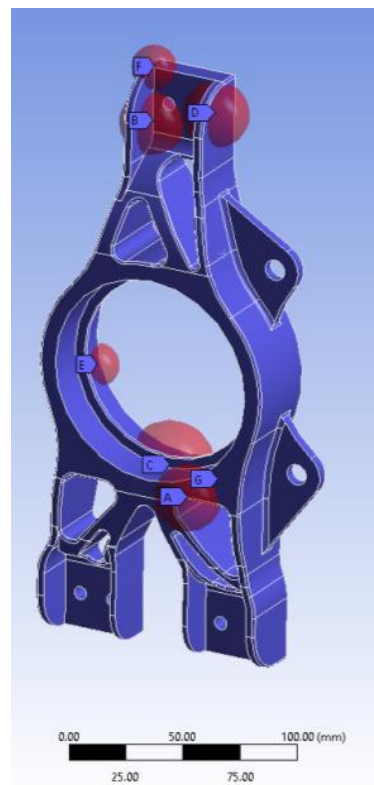

Fig. 1. Spheres of influence

Based on results, a $1 \mathrm{~mm}$ mesh element size was used in this sphere of influence as in Figure 1. All other spheres of influence were refined to a $2 \mathrm{~mm}$ mesh element size as these areas were aimed at reducing error and did not need as fine a mesh. Therefore, by refining the mesh in areas that needed to be refined instead of refining the whole model, a quicker, more efficient result can be found with high levels of accuracy.

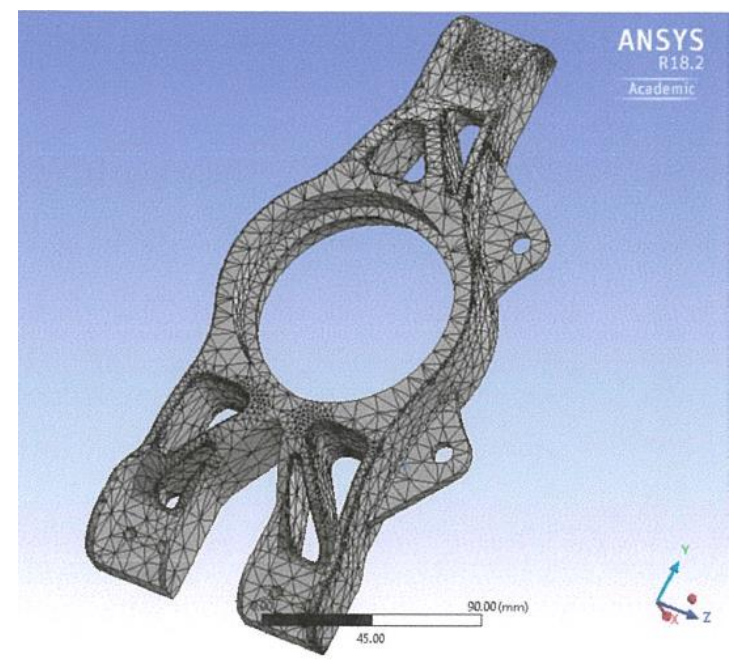

Fig. 2. Final mesh used for analysis of the upright

The boundary conditions of the model were introduced for spherical bearing connections occur at $40 \mathrm{~mm}$ in the $\mathrm{x}$ direction from the front edge of the upright to mount the upper and lower wishbone as well as the control arm. In order to simulate these bearing conditions, remote displacements were introduced. As the bearing is spherical, it was assumed that the boundary conditions were fixed in the Cartesian plane but free to move in the rotational degrees of freedom (Paula, 2005). This assumption was carried through for the upper and lower wishbone connection as well as the control arm. The geometry selection for these boundary conditions can be seen via the yellow surfaces in Figure 3 below. 


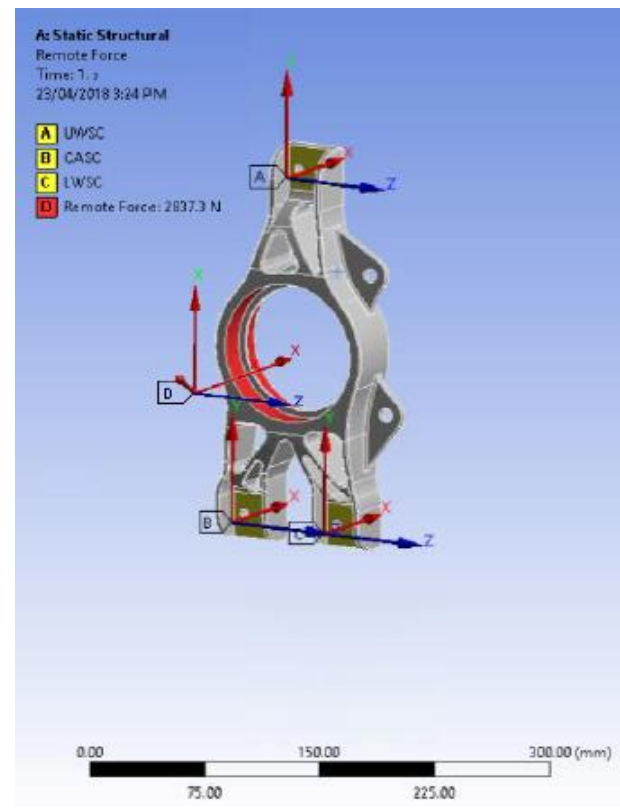

Fig. 3. Boundary conditions

These surfaces were chosen based on the assumption that the force in transferred from the geometry selections through the mounting brackets into the spherical bearing and not through the bolts. This assumption could be made through another assumption that the bolts only serve to connect the upright and the brackets and do not transfer load (Wirawan, 2018). In order to apply these remote displacement conditions three system coordinates had to be established. One to accommodate the upper wishbone connection, the lower wishbone connection and the control arm connection (Faidan,2008). The positioning of these coordinate systems relative to the global coordinate system were $(-40 \mathrm{~mm}, 120 \mathrm{~mm}$, $0 \mathrm{~mm}$ ) for the upper wishbone represented as A in Fig. 3, (-40mm, -120mm, 30mm) for the lower wishbone represented as C in Fig. 3 and $(-40 \mathrm{~mm},-120 \mathrm{~mm},-40 \mathrm{~mm})$ for the control arm represented as B in Fig. 3. These coordinates represent the center of the bolt holes for each connection and $-40 \mathrm{~mm}$ in the $x$ direction from the front face of the upright as seen in Figure 3.

Then the external forces were applied to the upright. These forces are relative to the center of the tyre patch and is equivalent to $-2360 \mathrm{~N}$ in the $\mathrm{x}$ direction and $1580 \mathrm{~N}$ in the $\mathrm{y}$ direction. Once again, a coordinate system was introduced to represent the center of the tyre patch. The coordinates relative to the global coordinate system were $13 \mathrm{~mm},-260 \mathrm{~mm}, 0 \mathrm{~mm}$ as in Figure 3. Once the coordinate system was added, a remote force of the aforementioned values was applied at this point. The surfaces where remote force acts through was chosen as the bearing surfaces which support the hub. These surfaces were chosen as it is the bearings that transmit the wheel patch forces through the suspension upright. With these boundary conditions and remote forces applied, a fully constrained model can be analyzed.

To determine whether the upright was safe to use, a static analysis was done. A fatigue analysis would have been conducted however, only the fatigue limit of the material is unknown. Thus an S-N curve cannot be generated, which is imperative for a fatigue analysis. Furthermore, details of fatigue loading are unknown, the static load case used represent the car cornering at $1.5 \mathrm{G}$ which is expected to be worst case scenario. The stresses found under the static analysis will be compared against the fatigue limit. It will be assumed for this analysis that if the static stress in below the fatigue limit, the upright will have an infinite life.

\section{Results and Discussion}

Upon conducting a verification and validation study the following results were observed. Figure 4 shows the results of a calculation verification study through a structural error analysis. The error seen 
was $0.17324 \mathrm{~mJ}$ though the value isn't dramatically small notice must be taken around the areas of maximum stress. In these areas, the observed error was $1.745 \times 10^{-10} \mathrm{~mJ}$, which is approximately zero. Therefore, further reduction of error was seen to only serve in decreasing the mesh size for areas where high accuracy was not needed. The validation studies are in below Table 2.The exact locations of the forces mentioned in Table 2 are represented in above Figure 3, as A for upper suspension linkage, B for control arm and $\mathrm{C}$ for lower suspension linkage.

Table 2. Validation of reaction forces

\begin{tabular}{|c|c|c|c|c|}
\hline Location & $\begin{array}{c}\text { Force Com- } \\
\text { ponent }\end{array}$ & $\begin{array}{c}\text { Theoretical } \\
(\mathbf{N})\end{array}$ & ANSYS (N) & Error (\%) \\
\hline \multirow{3}{*}{$\begin{array}{c}\text { Upper suspen- } \\
\text { sion linkage }\end{array}$} & $\mathrm{F}_{\mathrm{x}}$ & -1125 & -1199.5 & 6.62 \\
\cline { 2 - 5 } & $\mathrm{F}_{\mathrm{y}}$ & -1700 & -1675.2 & 1.46 \\
\cline { 2 - 5 } & $\mathrm{F}_{\mathrm{z}}$ & 60 & 67.6 & 12.62 \\
\hline \multirow{3}{*}{$\begin{array}{c}\text { Lower suspen- } \\
\text { sion linkage }\end{array}$} & $\mid \mathrm{F}$ & 2040 & 2031.4 & 1.05 \\
\cline { 2 - 5 } & $\mathrm{F}_{\mathrm{x}}$ & 1990 & 2034.0 & 2.21 \\
\cline { 2 - 5 } & $\mathrm{F}_{\mathrm{y}}$ & 275 & 288.9 & 5.06 \\
\cline { 2 - 5 } & $\mathrm{F}_{\mathrm{z}}$ & 220 & 222.1 & 0.94 \\
\hline \multirow{3}{*}{ Control Arm } & $\mid \mathrm{F}$ & 2020 & 2066.4 & 2.30 \\
\cline { 2 - 5 } & $\mathrm{F}_{\mathrm{x}}$ & 1495 & 1525.5 & 2.04 \\
\cline { 2 - 5 } & $\mathrm{F}_{\mathrm{y}}$ & -155 & -188.7 & 3.77 \\
\cline { 2 - 5 } & $\mathrm{F}_{\mathrm{z}}$ & -280 & -289.6 & 2.24 \\
\hline
\end{tabular}

According to the results in Table 2, the percentage error is less than $10 \%$ for all forces except for the force in the y direction of the control arm. However, when observing differences in forces, the difference between the simulated and expected y force of the control arm is only $34 \mathrm{~N}$. This one outlier is not enough evidence to render the validation study unsuccessful. Only two of the reaction force components are outside of the $10 \%$ limit and in most cases the reaction force components are within $5 \%$ of the theoretical value.

The equivalent von-Mises stress profile in Figure 4, high stress regions are observed to be around the bearing housing, with the maximum stress of $87.358 \mathrm{MPa}$ being observed in the upper regions of the leg that connects to the lower wishbone. The stress profile is justifiable through an analysis of the loading condition. The load is transmitted through the bearings so therefore it is to be expected that higher stress regions occur in the bearing housing. Furthermore, as all the spherical bearing connections are fixed in the Cartesian plane, moments generated in the connecting legs will also generate regions of higher stress.

As previously stated in Figure $4 \mathrm{a}$ and $\mathrm{b}$, the region of maximum stress is developed in the upper regions of the leg that connects to the lower wishbone this is to be expected when the geometry of the whole suspension is taken into account. The lower wishbone connection is where the suspension spring is connected to the suspension upright. Because of this, it would be expected that there is not only a force in the spherical bearing due to the wheel patch forces, but also due to the spring. Because of this, high stresses should occur in the leg connecting to the lower wishbone which is what can be observed. The detailed view of maximum stress area as in Figure $4 \mathrm{~b}$ shows that maximum stress occurs on the edge of the fillet, which is to be expected due to the stress raising characteristic of curved geometry.

After completion of the simulation of the suspension upright for the forces present in a typical $1.5 \mathrm{G}$ corner, it was determined that the maximum equivalent von-Mises stress of $87.358 \mathrm{MPa}$ was less than the fatigue limit of $90 \mathrm{MPa}$ and yield stress of $240 \mathrm{MPa}$. Because of this, it was determined that the current model has an infinite life that will not yield. However, as the maximum, von-Mises stress is only 2.6 MPa less than the yield factor, a slight increase in the wheel patch forces may mean that an infinite life may not attainable. A full fatigue analysis of the model will need to be undertaken in the future to 
determine this. In saying this, the maximum von-Mises stress is only $36.4 \%$ of the yield stress so failure will not occur.

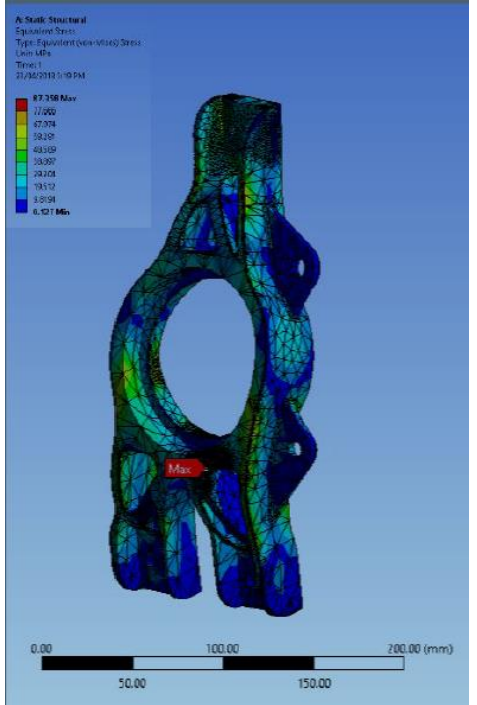

(a)

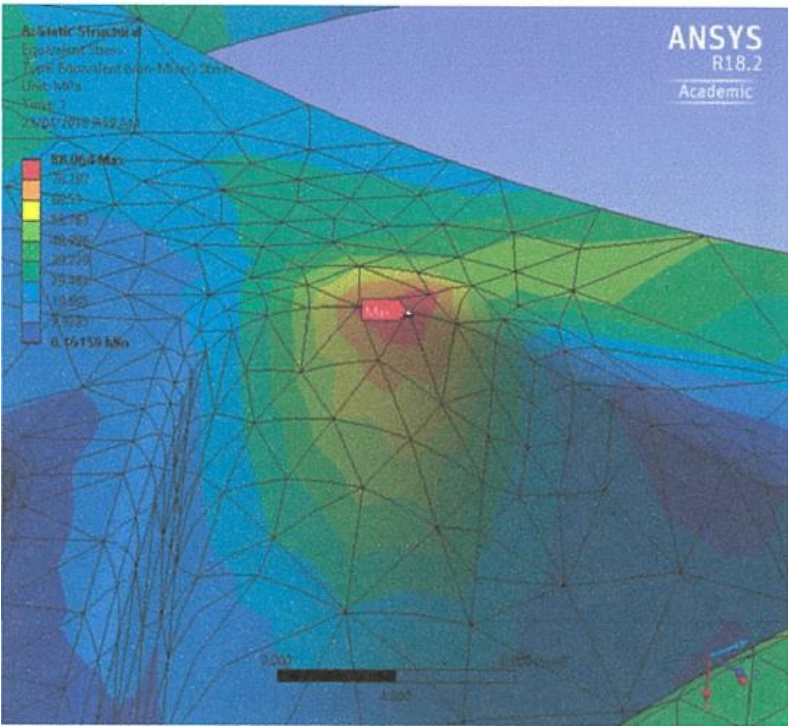

(b)

Fig. 4. (a) Von- Mises Stress Profile

(b) Detailed view of maximum stress location

The deformation profile in Figure 5 shows a maximum deformation of $0.21 \mathrm{~mm}$ on the lower bearing surface. Once again, this is to be expected due to the connection of the bearings to the axle. As the axle deflects when going into a corner, it is expected that the bearings should deform with it. Because the stiffness of the bearings is much higher than the stiffness of the upright, the bearing should deform the upright whilst the spherical bearing connections at the upper and lower wishbone and control arm do not deform as much due to being fixed in the Cartesian plane. Because this deformation of the bearing surface is on the bottom, it is expected that there should be larger deformations in the bottom control arm and lower wishbone connections than in the top upper wishbone connection which is what is observed

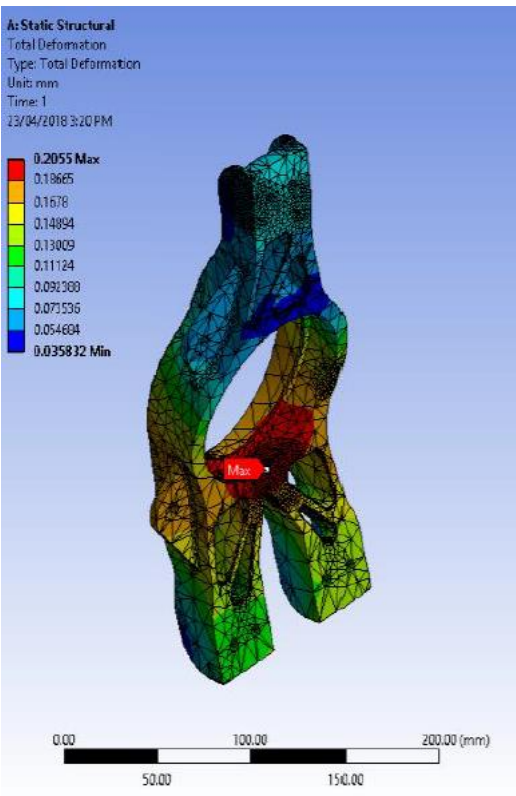

Fig. 5. Deformation Profile 
The confidence in these results comes from the verification and validation study. Calculation verification was undertaken with a mesh refinement study using spheres of influence. The accuracy of the model was increased in areas of high stress or high structural error. Therefore, the error of the model was dropped significantly to $0.17324 \mathrm{~mJ}$ and the error in places of high stress where high precision is necessary, an error of $1.745 \times 10^{-10} \mathrm{~mJ}$ which is approximately zero was observed. This gives confidence in the results due to the basically zero error in places where high accuracy is needed. Figure 6 below represents the structural error profile,

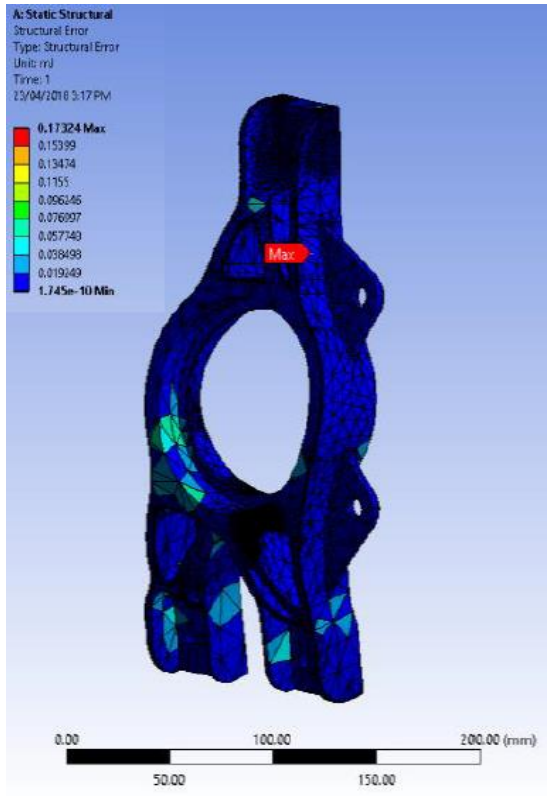

(a)

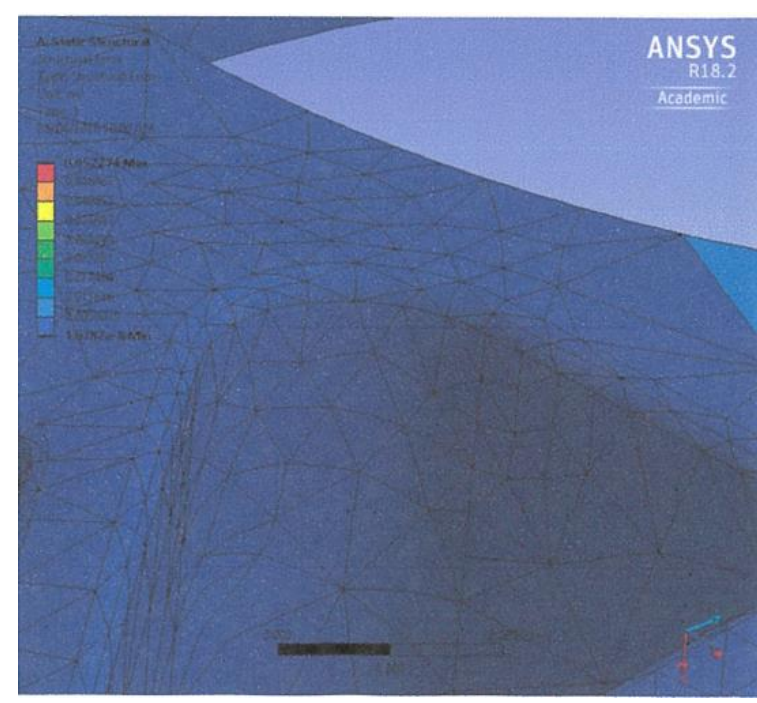

(b)

Fig. 6. (a) Structural error profile

(b) Structural error at maximum stress location

The validation process was conducted by comparison to expected forces at the upper and lower wishbone and the control arm. A percentage error analysis showed that all forces, bar one, were within a $10 \%$ range with many being within $5 \%$ of the expected values which is a suitable result. The one outlier which is $20 \%$ from its expected value does not give enough evidence to lose confidence in the validation study as it is still only $33 \mathrm{~N}$ away from its expected value. On top of this a force balance on the model can be seen to yield the wheel patch forces applied (i.e. $-2360 \mathrm{~N}$ in the $\mathrm{x}$ direction, $1580 \mathrm{~N}$ in the $\mathrm{y}$ direction and $0 \mathrm{~N}$ in the $\mathrm{z}$ direction). The results of the verification and validation study give confidence in the simulated results.

From the results gathered by this model simulation, improvements may be made to the design of the suspension upright. However, the critical stress $(87.358 \mathrm{MPa})$ is below that of the fatigue limit and yield stress (90 MPa and $240 \mathrm{MPa}$ respectively) of the material so these refinements may only be necessary if weight is of no issue. To reduce the maximum stress, thicker bearing housing may be applied as well as making the holes in the leg that connects to the lower spherical smaller. However, it must be emphasised that this is only necessary if weight is of no issue as the maximum stress is below that of the materials fatigue and yield limit. The factor of safety against fatigue limit is shown in According to Figure 7 below the minimum safety factor is 1.022 which means that the upright will last for an infinite life. 


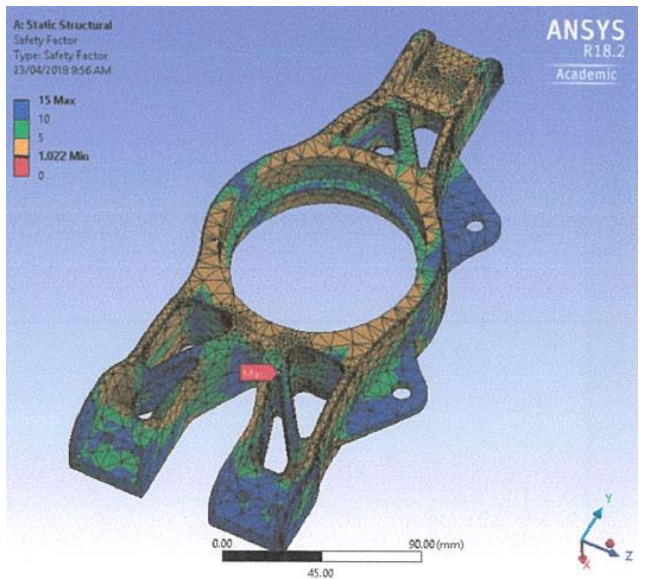

Fig. 7. Factor of safety against fatigue limit

\section{Conclusions}

In conclusion, a 6061-T6 aluminium suspension upright for a FSAE vehicle was modelled under the forces induced by a $1.5 \mathrm{G}$ corner. By modelling the upper and lower wishbones and the control arm as remote displacements with remote force acting from the centre of the tyre patch through the hub bearing surfaces, it was found that a maximum von-Mises stress and bearing deformation of $87.358 \mathrm{MPa}$ and $0.21 \mathrm{~mm}$ respectively were observed. Moreover it was determined that the upright is safe for use for infinite life given the fatigue limit of 90MPa. The stress profile and deformation were verified via investigating the structural error where the maximum structural error was $0.052 \mathrm{~mJ}$. The reaction forces found were compared against theoretical values for validation of the model. After comparison of the forces it was determined that the model was valid. Confidences in these results were a result of a verification and validation study where mesh refinements were made in order to gain high accuracy in places of high stress or structural error. Also, the simulated forces at the upper and lower wishbone connections were compared against expected values with accurate results. Therefore, improvements on the design are not necessary but may be introduced if weight is of no issue.

\section{References}

Agarwal. S and Saatyaki. T. (2020) Fatigue analysis and optimization of upright of a FSAE vehicle, International Journal of Engineering Research and Technology, Volume 9, Issue 3.

Dhakar, A and Ranjan, R. (2016). Force calculation in upright of a FSAE race car, International Journal of Mechanical Engineering and Technology, 7(2), 168-176. Retrieved from https://www.researchgate.net/publication/341623254_FORCE_CALCULATION_IN_UPRIGHT_OF_A_FSAE_RACE_CAR

Faidan,I., Mcgough, A.,Foote, F.,(2008) The development stages of rear upright for formula car. International Mechanical Engineering Congress and Exposition. https://doi.org/10.1115/IMECE2004-60286

Giovanni ,V., Luca, R., Lorenzo, F., Giovanni, F., (2015). Development of an engine variable geometry intake system for a formula SAE application, Energy Procedia, 81(1) 930-941:

Paula, E.D. (2005) Formula SAE suspension Design SAE Technical Paper, https://doi.org/10.4271/2005-01-3994 
Robert, D. and Delagrammatikas, G. ( 2010). The suspension system of the 2009 Cooper union FSAE Vehicle: a comprehensive design review, Journal of Passenger Cars-Mechanical Systems https://doi.org/10.4271/2010-01-0311

Saurabh. S., Kumar . S., Jain .K and Gandhi. D.(2016). Design of suspension system for a formula student race car, Procedia Engineering, 144: 1138-1149. Retrieved from https://www.researchgate.net/publication/303534778_Design_of_Suspension_System_for_Formula_Student_Race_Car.https://doi.org/10.1016/j.proeng.2016.05.081

Schommer, A., Soliman, P., Faris, L., and Martims, M. (2015). Analysis of a formula SEA vehicle suspension: Chasis tuning SAE Technical Paper. https://doi.org/10.4271/2015-36-0275

Sneh. H., Mandar.G., Ajay.B.K., Yagnavalkay. M. (2014). Aerodynamics study of Formula SAE car, Procedia Engineering, 97 (1): 1198-1207, https://doi.org/10.1016/j.proeng.2014.12.398

Wirawan. J., Aditra, R., Almursyah, R., etal. (2018). Design analysis of formula student race car suspension system, AIP Conference Proceedings. https://doi.org/10.1063/1.5024110 